УДК 316.354

\title{
ДИСТАНЦИОННОЕ ОБУЧЕНИЕ В РОССИИ И ЕГО СПЕЦИФИКА В ПЕРИОД РАСПРОСТРАНЕНИЯ КОРОНАВИРУСНОЙ ИНФЕКЦИИ SARS-COV-2
}

\author{
Марголис Ольга Викторовна \\ учитель \\ ГБОУ города Москвы «Школа №1883 «Бутово»
}

\begin{abstract}
Аннотация: Пандемия COVID-19 привела к временному переходу на дистанционный формат обучения образовательных учреждений во всем мире. В работе рассмотрены модели и формы организации обучения в период дистанционного обучения текущего учебного года в России. В статье анализируются опросы, посвященные отношению родителей и учеников к дистанционному обучению в период распространения новой коронавирусной инфекции SARS-COV-2, вызвавшей пандемию COVID-19. Подчеркивается, что дистанционная форма обучения не должна являться цифровой реализацией очного обучения.
\end{abstract}

Ключевые слова. Дистанционное обучение, образование, образовательная платформа, коммуникационные интернет-сервисы, социальные сети, мессенджеры, видеоконференции.

\section{DISTANCE LEARNING IN RUSSIA AND ITS SPECIFICS DURING THE SPREAD OF SARS-COV-2 CORONAVIRUS INFECTION}

\section{Margolis Olga Viktorovna}

Abstract: The COVID-19 pandemic has led to a temporary transition to distance learning in educational institutions around the world. The paper considers the models and forms of organization of training during distance learning in the 
current academic year in Russia. The article analyzes surveys on the attitude of parents and students to distance learning during the spread of the new coronavirus infection SARS-COV-2, which caused the COVID-19 pandemic. It is emphasized that distance learning should not be a digital implementation of full-time learning.

Key words: Distance learning, education, educational platform, Internet communication services, social networks, messengers, video conferences.

Весной 2020 года пандемия COVID-19 привела к неожиданному и масштабному переводу учебных заведений на дистанционный формат обучения. Педагоги, учащиеся и родители были не готовы к такому развитию ситуации. Участники образовательного пространства адаптировались к новым условиям в максимально короткие сроки. Сегодня многие педагоги продолжают использовать в своей работе опыт, новые знания, полученные в период дистанционного обучения. Конечно, положительные эффекты дистанционного образования необходимо использовать для дальнейшего развития процесса обучения и преподавания, чтобы сделать его интересным, доступным и индивидуальным.

В 2020-2021 учебном году при организации дистанционного обучения учебные заведения использовали две модели: полное прекращение очного обучения и частичное, когда карантин распространялся на отдельный класс (группу), индивидуально для учащегося (студента) или преподавателя (рис. 1). 


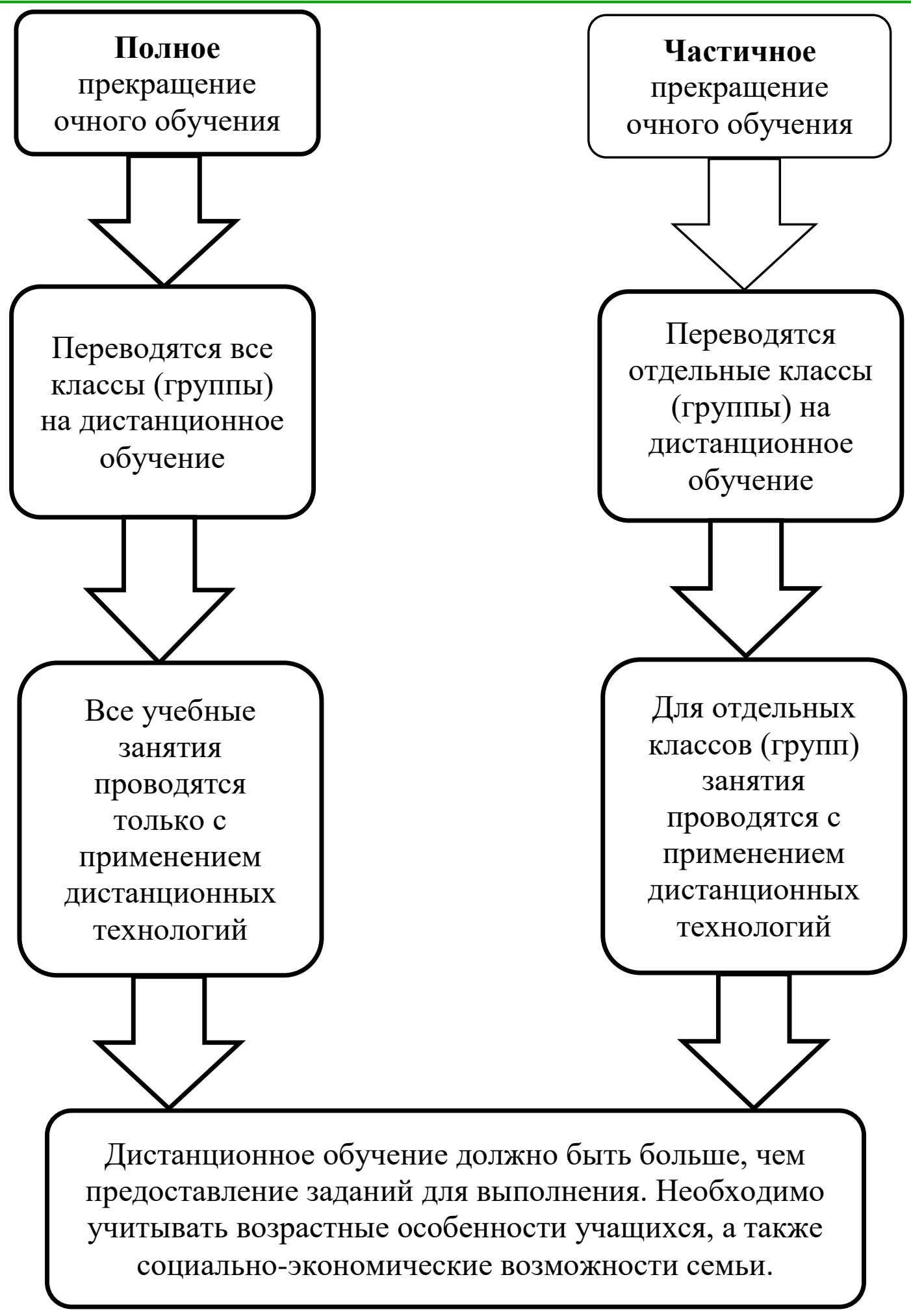

Рис. 1. Модели дистанционного обучения

На практике дистанционное обучение состоит из двух форм: онлайн (дистанционные) занятия и офлайн (электронные) занятия [1]. Онлайн занятия позволяют сохранять привычный распорядок дня участников образовательного процесса и предполагают совместное (синхронное) использование учителем и учащимися одного из коммуникационных сервисов. Он позволяет организовать 
общение учителя и учеников (группы учеников) в режиме видеоконференций, демонстрировать экрану цифровую доску, делиться учебными материалами. Это могут быть образовательные платформы, которые позволяют учителям и ученикам подключаться к виртуальным классам, переходить из класса в класс между уроками. Офлайн занятия могут рассматриваться как время самостоятельной работы, когда обучающиеся могут выбрать комфортные для себя время и темп работы, электронные занятия предполагают выполнение конкретных заданий учениками, которые преподаватель предоставляет с помощью образовательных платформ (цифровые задания) или публикации рабочего листа в электронном дневнике [2]. Однако, офлайн занятия могут приводить к нарушению привычного распорядка дня учащихся. Обе формы должны использоваться в процессе дистанционного обучения, с учетом возрастных особенностей учащихся, а также чередоваться друг с другом. Возможно совместное использование двух форм в период одного учебного занятия.

Результаты опроса ОНФ «Равные возможности - детям» и фонда «Национальные ресурсы образования» показали, что треть опрошенных детей способна к самоорганизации: они продолжают вести привычный образ жизни, планируют свой день, способны в период дистанционного обучения узнать больше, чем на очных уроках, видят для себя новые возможности, проявляют интерес к новой форме обучения. В отличие от этой группы учащихся другая более пассивна: около 50\% чувствуют повышенную утомляемость, $65 \%$ считают, что в процессе очного обучения легче понимать и запоминать новый материал [3]. Как видно, дистанционное образование в России имеет своих сторонников и противников. Сторонники дистанционного образования считают, что при грамотном подходе к организации учебного процесса с применением цифровых технологий, есть возможность получить более качественное образование, чем в условиях очного обучения $[4,5]$. Противники дистанционного обучения указывают на недостаток общения учащихся с педагогами, перегрузку и частые перебои в работе образовательных платформ и коммуникационных сервисов, отсутствие в семьях технических средств и программного обеспечения для организации дистанционного обучения - все эти факторы, по их мнению, ведут к снижению уровня знаний [5]. Негативным фактором является и сравнение участниками образовательного процесса дистанционного обучения с традиционным выполнением домашних заданий. Исследование показало, около $50 \%$ родителей берут на себя функции педагога 
и оказывают поддержку своим детям при выполнении заданий в период дистанционного обучения. Однако ввиду того, что многие родители заняты на рабочем месте полный день или в семье воспитываются несколько детей, которые одновременно получают образование дистанционно, не каждый учащийся имеет возможность получить полноценную педагогическую поддержку со стороны родителей $[6,7]$.

Обратная связь и диалог с учащимися являются важными составляющими учебного процесса. В период дистанционного обучения общение с преподавателем играет огромную роль в способности учащихся оценить свой прогресс в обучении и сохранить мотивацию к учебе [8, 9, 10]. Таким образом, успех дистанционного обучения зависит не только от того, насколько качественно выполнит ученик задания, соответствующие учебной программе, но и от организации совместного диалога между участниками образовательного процесса. Качество полученных знаний учеником зависит от того, будет ли ктото сопровождать ребенка, поощрять его успехи в обучении и побуждать думать дальше.

Важно понимать, что дистанционная форма обучения не должна являться цифровой реализацией очного обучения. Дистанционное обучение само по себе более индивидуализированное, чем совместная работа в группе (классе), оно предполагает возможность отказа от фиксированного места и времени, когда все должны выполнять одно и то же задание, дает возможность выбора комфортной среды для учащихся с ограниченными возможностями. В зависимости от возрастных особенностей, можно показать учащимся, что с помощью цифровых образовательных ресурсов достигается успех в обучении без строго контроля со стороны педагога. При этом ученик должен иметь возможность в любое время задать свой вопрос учителю, если у него возникли затруднения или какое-либо непонимание при выполнении задания. Благодаря самостоятельной работе в период дистанционного обучения учащиеся развивают и совершенствуют способность выполнять поставленную задачу осознанно и ответственно.

\section{Список литературы}

1. Крук Б.И. Избранные главы теории и практики дистанционного обучения: Учебное пособие // Б.И. Крук. М.: Юрайт, 2019. 202 с.

2. Милушкина О.Ю., Попов В.И., Скоблина Н.А., Маркелова С.В., Соколова Н.В. Использование электронных устройств участниками образовательного процесса при традиционной и дистанционной формах 
обучения // Вестник Российского государственного медицинского университета. 2020. № 3. С. 85 - 91 .

3. Опрос «Оценка дистанционного обучения родителями и школьниками» проекта ОНФ «Равные возможности - детям» [Электронный pecypc]. URL: https://onf.ru/2020/04/14/onf-predstavil-itogi-oprosa-ocenivshihdistancionnoe-obuchenie-roditeley-i-shkolnikov/

4. Ярославцева К.А., Царенкова В.Б. Специфика дистанционного обучения в России // Вестник науки и образования. 2020. Ч.1 № 19 (97).С.47-49.

5. Опрос «Борьба с собой или новые возможности»: дистанционное обучение глазами школьников и родителей по данным опросов Фонда» Фонда общественного мониторинга развития системы образования «Национальные ресурсы образования» [Электронный ресурс]. URL: https://nro.center/news/borbas-soboj-ili-novye-vozmozhnosti-distancionnoe-obuchenie-glazami-shkolnikov-iroditelej-po-dannym-oprosov-fonda/

6. Николаева Е.И., Дунаевская Э.Б., Калабина И.А. Факторы, влияющие на успешность поддержки родителями детей при дистанционном обучении // Комплексные исследования детства. 2020. Т. 2. № 4. С. 235 - 245.

7. Мизина О.А. Психологическое сопровождение детей-инвалидов в условиях дистанционного обучения // Известия ДГПУ. 2014. № 2. С. 12 - 16.

8. Семенова Г.В., Гусева Ю.Е., Поссель Ю.А. Структура психологической готовности к использованию дистанционных образовательных технологий у педагогов // Научное обеспечение системы повышения квалификации кадров. 2019. № 2 (39). С. 71 - 79.

9. Schneider, R., Schipolowski, S., Sachse, K.A., Enke, F. \& Stanat, P. Fernunterricht im Schuljahr 2019/2020: Ergebnisse der Lehrkräfte-befragung des IQB. Berlin: Institut zur Qualitätsentwicklung im Bildungswesen. 2020. https://www.iqb.hu-berlin.de/bt/Fernunterricht/IQB_Lehrkrftebef.pdf

10. Huber S.G., Helm Ch. Lernenin Zeiten der Corona-Pandemie // Die Deutsche Schule, 2020. Beiheft 16. S. $37-60$.

(C) О.В. Марголис, 2021 